\title{
Propuesta para un diagnóstico sociolingüístico de poblaciones minorizadas en Cartagena. Aproximación a su diversidad lingüística y sociocultural ${ }^{1}$
}

\author{
Doris Fagua Rincón ${ }^{2}$ \\ Universidad de Cartagena \\ ORCID: 0000-0002-4578-0683 \\ Diana Padilla Torres ${ }^{3}$ \\ Universidad de Cartagena \\ ORCID: 0000-0003-3405-312X \\ Recibido: 15 de enero \\ Aceptado: 25 de febrero
}

\section{Resumen}

En la actualidad, Cartagena de Indias, urbe en desarrollo, puerto y destino turístico, acoge, además de los visitantes y su población tradicional, grupos de diferentes orígenes geográficos y étnicos. La movilidad de estas poblaciones es en algunos casos histórica, como la de los criollos palenqueros, los rroms o los chinos, mientras que la de otros grupos es más reciente: criollos isleños, indígenas del resto del país: koguis, ikas,

\section{Summary}

At present, as a developing city, port and tourist destination, Cartagena de Indias welcomes groups of different geographical and ethnic origins, in addition to tourists and its traditional population. The mobility of those populations is in some cases historical, such as that of the Palenquero Creole, Rrom, or Chinese; while that of other groups is more recent: island Creoles, indigenous people from the rest of the country such as: Ko-

1 Proposal for a sociolinguistic diagnosis of minorized mopulations in Cartagena. Approach to its linguistic and sociocultural diversity

2 Doctora en Lingüística Descriptiva, Teórica y Automática, Universidad Paris 7, Paris Diderot. Magíster. en Lingüística, Universidad Nacional de Colombia, Magister. en Lingüística Descriptiva, Teórica y Automática, Universidad Paris 7, Paris Diderot. Correo: dfaguar@unicartagena.edu.co

3 Magister en Lingüística (Universidad de Antioquia). Profesional en Lingüística y Literatura (Universidad de Cartagena). Correo: dpadillat@unicartagena.edu.co 
wayúus, zenúes (Costa caribe), nasas e ingas (Andes). También se encuentran hablantes de Lengua de Señas de Colombia (en adelante LSC) y la reciente ola de ciudadanos venezolanos. Las implicaciones de tal cohabitación (relaciones de dominación, acceso inequitativo a la ciudadanía, bienes y servicios, la pérdida de lenguas y los valores culturales que ellas vehiculan, etc.), no obstante, son poco conocidas por parte tanto de la población anfitriona como de las instancias de administración local. Se plantea aquí, como propuesta de aproximación a esta diversidad lingüística y sociocultural, el desarrollo de un diagnóstico sociolingüístico en colaboración con las diversas poblaciones que convergen en la ciudad. Desde los planteamientos teóricos y metodológicos tradicionales $\mathrm{y}$ actuales de la sociolingüística y la antropología lingüística, esta propuesta podrá contribuir al reconocimiento y valoración de la (super)diversidad, así como a la toma de decisiones que garanticen la coexistencia armónica en la ciudad y sus alrededores con poblaciones de origen diverso.

Palabras clave: poblaciones étnicas urbanas, diagnóstico sociolingüístico, Cartagena, diversidad lingüística y sociocultural guis, Ikas, Wayúus, Zenu (Caribean Cost), Nasa and Inga (Andes mountains). There are also speakers of Colombian Sign Language (LSC) and the recent wave of Venezuelan citizens. The implications of such cohabitation (relations of domination, inequitable access to citizenship, goods and services, the loss of languages and the cultural values that they convey, etc.), however, are little known by both the host population and the local administration instances. It is proposed here, as a proposal of approach to this linguistic and sociocultural diversity, the development of a sociolinguistic diagnosis in collaboration with the diverse populations that converge in the city. From the traditional and current theoretical and methodological approaches of sociolinguistics, and linguistic anthropology, this proposal can contribute to the recognition and appreciation of (super)diversity, as well as to the decision making that guarantees the harmonious coexistence in the city and its surroundings with populations of diverse origin.

Key words: urban ethnic populations, sociolinguistic diagnosis, Cartagena, linguistic and sociocultural diversity 


\section{Introducción}

La diversidad lingüística y cultural de Colombia es a menudo desconocida por la población en general, así como por instancias privadas e incluso gubernamentales. Este desconocimiento acarrea el riesgo de pérdida de la diversidad en la medida en que el español se impone como lengua vehicular de poblaciones de tradición no hispanohablante y aumenta las brechas entre los diferentes actores de la sociedad (Pachón, 1997; Ardila, 2012). Esta situación puede ser particularmente crítica en contextos de ciudad, centros poblados y sus periferias que acogen una inusitada y creciente población migrante de áreas rurales. Tal cohabitación se traduce en diferentes formas de inequidad social: exclusión, fracaso escolar, negación de la identidad ancestral, adopción de la lengua y la cultura de la mayoría (Ferguson, 1989 [1959], Kauffman y Thomason, 1998) o hibridación (Godenzzi, 2017). A largo plazo, las desigualdades pueden convertirse en tensiones sociales y conflictos más marcados (Vertovec, 2007; Pérez, 2012), con fenómenos como la desciudadanía (Heller, 2013).

En lo que sigue pasaremos revista por los temas de investigación que hemos identificado de manera preliminar, mayormente partiendo de nuestra propia observación como habitantes de la ciudad, estudiantes y docentes de la Universidad de Cartagena, con historias de vida próximas o alejadas de esta ciudad-región. Lo anterior pone, pues, de relieve la pertinencia de indagar acerca de problemas poco explorados a pesar de hacer parte de la interacción cotidiana dentro de la aglomeración.

Enmarcada en esta realidad, Cartagena y su periferia requieren el conocimiento y visibilización de su diversidad sociocultural. Con el fin de contribuir en esta tarea destacamos la necesidad de describir el perfil sociolingüístico de la ciudad que, además de proporcionar un inventario de las lenguas presentes, permitiría ofrecer una caracterización de las poblaciones de diversos orígenes que allí convergen y de las implicaciones que este contacto -que sabemos desigual- tiene en el acceso a la ciudadanía.

La propuesta parte de una revisión del estado de la cuestión. La implementación de esta propuesta podría a mediano o largo plazo constituirse en referente para el desarrollo de diagnósticos de este tipo en medios urbanos. Las pautas teóricas y metodológicas necesarias para describir y analizar las distintas relaciones de coexistencia y tensiones en la comunidad de estudio, así como las consecuencias del contacto de lenguas, son proporcionadas por la sociolingüística 
(Holmes y Meyerhoff, 2011; Bush, 2015), la antropología lingüística y la etnografía de la comunicación (Vertovec, 2007; Heller, 2013; Hymes 1972, Guber, 2001).

\section{Coexistencia entre poblaciones y lenguas: inequidad y tensión}

La diversidad sociocultural y lingüística de las poblaciones que convergen en la ciudad puede ser aprehendida y vivida como un obstáculo para la intercomprensión y la inclusión, cuando tal diversidad se enmarca en formas de relacionamiento asimétricas entre las poblaciones locales, inmigrantes y las instituciones y entidades representantes del Estado. Las relaciones asimétricas se materializan en un acceso desigual a servicios y derechos como la educación, el trabajo, la salud, el ejercicio de la ciudadanía y toda otra forma de inequidad social (Appel y Muysken, 2005; Léglise, 2017; Oakes y Warren, 2007; Heller, 2013).

Esta inequidad social se deriva, en gran medida, del desconocimiento de la presencia misma de estas poblaciones en la ciudad, tanto por parte de la población general como de las diferentes instancias públicas y privadas que funcionan como entes prestadores de servicios o simplemente como lugares de encuentro. En ocasiones, el desconocimiento del otro se sustituye por la circulación de discursos activadores de estereotipos racistas o xenófobos que suplantan otras alternativas de acercamiento a la alteridad (Blommaert y Rampton, 2011). Paradójicamente, esta situación es paralela al surgimiento de una conciencia colectiva que, por diversos medios y acciones, reconoce la pluralidad y el valor de la diversidad.

Asumimos que la valoración de la diversidad es una condición necesaria para una cohabitación armónica y ella implica en primerísima instancia un mínimo (re)conocimiento y la visibilidad de aquellos que se instalaron o se instalan en la ciudad y su periferia. Esta diversidad requiere, desde el ejercicio investigativo, proporcionar información sociolingüística básica que de un lad|10 contribuya a la identificación de las diversas poblaciones que convergen en la ciudad: caracterizarlos, conocer sus orígenes geográficos y su distribución en la ciudad, sus alrededores, el país y/o el mundo. También, permite aproximarnos a sus raíces socioculturales y a la situación de vulnerabilidad de sus lenguas y culturas, concientizando a los diferentes actores sociales de la amenaza de pérdida cultural y lingüística a la que se enfrenta la población que se desplaza e instala en la ciudad. Por lo demás, este tipo de investigación, como lo señalan Blommaert y Rampton (2011), podrá contribuir a la reflexión teórica en torno a las tendencias de la actividad comunicativa y las ideologías subyacentes. 
Es así necesario construir un primer perfil de la diversidad sociocultural y en particular del panorama sociolingüístico de la ciudad, es decir, el grado de vitalidad de las lenguas y los factores que inciden positiva o negativamente en su conservación. Para ello será necesario indagar sobre cuáles son y dónde se encuentran las poblaciones de raíces étnicas o lingüísticas diferentes a las de la población cartagenera tradicional.

Interesa, además, conocer los ámbitos de interacción de estas poblaciones con la población e instituciones locales y/o nacionales. Habría que estudiar las relaciones mediadas por la lengua entre los actores, en ámbitos de relaciones jerárquicas u horizontales, discriminatorias o incluyentes, así como los sistemas de organización de estas poblaciones, ya sea en comunidades, núcleos familiares, o personas que han migrado a la ciudad a título individual. Observar los espacios en los que convergen e interactúan estas poblaciones o personas permitirá dar cuenta de relaciones asimétricas (Hymes, 1967) y en general caracterizar su situación sociolingüística. Es de destacar que tales relaciones deben hoy ser vistas desde una complejidad mayor que implica no el contacto de lenguas y culturas homogéneas sino de urbes superdiversas (Vertovec, 2007; Blommaert, 2011; Blommaert y Rampton, 2011), en donde el plurilingüismo y formas heterogéneas de interacción (Léglise y Sánchez, 2018), como la hibridación (Godenzzi, 2017), marcan dinámicas de reconocimiento de sí y del otro.

Así, un enfoque sociolingüístico permite indagar sobre si las variedades lingüísticas ( $c f$. lenguas, dialectos, registros) son habladas en la ciudad por poblaciones migrantes de reciente o larga instalación en la ciudad, los tipos y grados de dominio de variedades ( $c f$. bilingüismo/ monolingüismo) que pueden ser identificados; los factores que determinan la vitalidad o amenaza de pérdida de las lenguas o variedades lingüísticas en la ciudad; la distribución de funciones (formales, informales) de las variedades lingüísticas dominantes (cf. español cartagenero) y de las variedades lingüísticas de las poblaciones que han migrado a Cartagena (criollos palenquero o raizal, kogui, ika, rrom, wayuu, chino, venezolano, LSC, etc.). Además, se hace necesario identificar cuáles son los espacios reservados a estas variedades lingüísticas en ámbitos de la esfera familiar o privada y en ámbitos institucionales (escuelas, colegios, universidades, centros culturales, dispensarios, hospitales; entidades estatales y departamentales, entre otros) y los posicionamientos e identidades que subyacen a la elección de una u otra variedad lingüística (Sánchez, 2018).

Los elementos de indagación esbozados en lo que precede permitirán colmar un vacío de información respecto a la situación de 
convergencia en la ciudad de lenguas y grupos que las hablan en dinámicas aceleradas de cambio. Esta situación se explica, en parte, por una cohabitación relativamente reciente e inusual de poblaciones de diversos orígenes en la ciudad de Cartagena -y, en general, en las urbes colombianas-. Tales dinámicas sobrepasan la capacidad de las diferentes instancias de administración local para reaccionar y dar respuesta a los desafíos de una convivencia armónica y el ejercicio de la ciudadanía equitativa.

La adopción de medidas eficaces para la salvaguardia de las lenguas y culturas que coexisten en la ciudad requiere de una descripción disponible del panorama sociocultural de las ciudades, en general; y de las prácticas comunicativas de los actores sociales, en particular. Tal información contribuirá a una mejor comprensión, tanto de las manifestaciones y posibles causas de las relaciones asimétricas entre poblaciones y variedades lingüísticas, como de la amenaza inminente y creciente para la preservación de la diversidad sociocultural del país.

Desde la academia y a partir de un trabajo colaborativo con las poblaciones y comunidades, piezas del mosaico sociocultural de la ciudad que acepten el reto de participar en tal estudio, se podría, entonces, ofrecer un primer esbozo del panorama sociolingüístico de Cartagena que contribuya al (auto)reconocimiento y (auto)valoración de las diferentes poblaciones convergentes, desde su diversidad sociocultural.

\section{Estudios sociolingüísticos en Colombia}

En nuestro país, Pachón y Correa (1997) dan cuenta de la preocupación de académicos a finales del siglo XX, frente a las condiciones de amenaza inminente de pérdida cultural y lingüística -en realidad todas las lenguas del país, excepto el español-. A partir de los años 2000, se publican estudios pioneros sobre problemas derivados del contacto de lenguas y culturas indígenas de resguardos y comunidades rurales de algunos departamentos de Colombia (Amazonas: Rey, 2001; Rodríguez, 2004; Cauca: Chaparro, 2007; Solano, 2008), entre ellos algunos desarrollados con población indígena de ciudades y su periferia (Amazonas: Fagua, 2001 (2004); Vichada: Ramírez, 2003). A través del Programa de Protección a la Diversidad Etnolingüística (PPDE, 2009), el Ministerio de Cultura, adelantó la formación de miembros de los diferentes grupos étnicos del país para desarrollar, en el marco de la conservación del patrimonio inmaterial de la nación, autodiagnósticos sociolingüísticos en sus resguardos y 
territorios ancestrales (Ministerio de Cultura, 2011). En 2012, Olga Ardila proporcionó el panorama lingüístico del país, que incluye un balance alarmante de pérdida de la diversidad sociolingüística.

En la última década, este tipo de estudios, a nivel mundial, se concentra menos en las lenguas como unidades discretas que entran en contacto, mezclándose y alternando, y se enfoca más en las prácticas comunicativas de los individuos en las que el plurilingüismo y el multilingüismo son la tendencia y no la excepción (Léglise y Sánchez, 2018). Además, se observa un énfasis en el uso que hacen los hablantes de sus recursos lingüísticos para producir y negociar significados sociales (Léglise y Sánchez, 2018). Estas descripciones se enmarcan desde la perspectiva de la interacción social y desde la mirada de los actores e investigadores del Sur. Siguiendo esta perspectiva, en Colombia se destacan los trabajos de Sánchez Moreano $(2017,2018)$ que describen las prácticas comunicativas de los quichuas de Cali. Allí, la ciudad es vista como un espacio sociolingüístico de negociación de identidades y posicionamientos sociales, comparables a las encontradas en el estudio de caso de Godenzzi (2017) en donde los recursos lingüísticos de quechuahablantes, que han migrado a Lima, ensayan estrategias de hibridación que configuran la identidad de poblaciones que se establecen en la ciudad.

Por otra parte, podemos mencionar publicaciones no académicas en páginas web institucionales que versan sobre iniciativas de inclusión en instancias de administración local. Por ejemplo, las alcaldías de Bogotá, Cali y Cartagena hacen mención de programas de inclusión en sus planes de acción, aunque de manera incipiente. En Bogotá, la Secretaría de planeación ha emprendido diversas acciones de inclusión de lenguas étnicas y de señas en escuelas y colegios distritales. Sin embargo, es mucho lo que resta por hacer en las ciudades colombianas para poder tener un conocimiento más preciso de las realidades sociolingüísticas locales.

\section{Pertinencia de un diagnóstico sociolingüístico de Cartagena}

Tanto en el contexto nacional actual como en el global, los desplazamientos hacia las urbes motivados o forzados por razones de distinta índole (económica, social, política, etc.), se han acentuado, poniendo en contacto poblaciones citadinas con otras que, histórica o tradicionalmente, ocupaban espacios geográficos diferentes. Esta situación ha complejizado o creado nuevas formas de relacionamiento en la ciudad (IOM y Agencia de migración de la ONU, 2018). Habría que subrayar una movilidad que no es exclusivamente transfronteriza, sino que tiene 
lugar al interior de países y regiones, como en el caso que nos ocupa. Aquellas poblaciones que han abandonado sus territorios de origen para instalarse en las urbes pueden ser especialmente vulnerables a la pérdida acelerada de su bagaje cultural y lingüístico. En efecto, se calcula que, para finales de siglo, la mitad de las aproximadamente 7000 lenguas del mundo habrá desaparecido, algunas de ellas sin dejar registro de su existencia ni del enorme legado de conocimientos milenarios que vehiculan y transmiten (Harrison, 2016: 3). La migración de los lugares de origen hacia ciudades acelera el riesgo de no transmisión intergeneracional de lenguas y culturas. En algunos grupos esta pérdida es inminente.

En Colombia, además del español, según distintas fuentes, habría alrededor de 70 lenguas indígenas, dos criollas (palenquero y sanandresano), la LSC y la lengua rrom (Ardila 2012; Landaburu, 20042005). Con excepción del español, todas ellas están amenazadas de extinción en diferentes grados.

Las cifras arrojadas por el último censo y las proyecciones del DANE (s.f., 2007) revelan una inversión de la distribución geográfica de las poblaciones étnicas respecto al censo de 1993. En efecto, este último nos muestra, por ejemplo, que la población indígena se encontraba mayoritariamente en sus territorios ancestrales, mientras que para el 2005, se constata su instalación progresiva y en crecimiento en cabeceras municipales y centros urbanos.

Cartagena de Indias no ha sido ajena a ese escenario de flujo de personas, pues en ella convergen poblaciones de orígenes lingüísticos y socioculturales diversos ${ }^{4}$. Entre ellos, hablantes de lenguas indígenas de la región caribe que afluyen a la ciudad en búsqueda de empleo formal e informal o acceso a la educación básica y superior (wayuús, koguis, ikas). De estos pueblos no se cuenta con bibliografía sobre situaciones de migración hacia las urbes. Los zenúes, por su parte, son indígenas descendientes de un pueblo que ya para mediados de siglo pasado había dejado de transmitir su lengua a las jóvenes generaciones, según datos reportados en trabajos arqueológicos de Reichel-Dolmatoff (1957). A parte de esos estudios arqueológicos

\footnotetext{
4 Esta información sobre los grupos étnicos y migrantes extranjeros fue obtenida gracias a una exploración preliminar adelantada con el grupo de estudiantes de séptimo semestre que seguían la asignatura de Antropología Lingüística del Programa de Lingüística y Literatura de la Universidad de Cartagena, durante el segundo semestre de 2017.
} 
y antropológicos (Turbay, 1992), no se reportan trabajos académicos recientes sobre este pueblo, su relación con la ciudad ni su proceso de recuperación lingüística. Se sabe que reconocen sus orígenes y mediante acciones activistas reivindican la recuperación de tierra, su lengua y cultura. Recientemente, su presencia ha sido notada por los cartageneros a través de la prensa escrita local que cubría la ocupación de tierras por un cabildo de Membrillal (Flórez, 2012; Goez, 2018).

El criollo palenquero de base léxica española hace parte de la identidad de la aglomeración de Cartagena. Con un trasfondo turístico, recientemente se ha dado un reconocimiento simbólico, por parte de la población e instancias locales, de la presencia e historia palenqueras como propias. Algunos estudios se han ocupado de las relaciones entre las poblaciones (Salgado, 2011; Arrázola, 1970; Friedmann, 1983; Navarrete, 2008). Otros, además de tales relaciones, también describen niveles lingüísticos (Schwegler y Moñino, 2002; Dieck, 2011). En fin, se trata de la descripción de rasgos lingüísticos en diferentes niveles compartidos con la subvariedad dialectal cartagenera, del superdialecto costeño del Atlántico (Del Castillo, 1982; Patiño, 1983). Sabemos que también hay criollos raizales, cuya lengua es de base léxica inglesa. Se adolece, sin embargo, de información disponible sobre su asentamiento en la ciudad y las dinámicas de interacción con la población local

De los rrom de Cartagena contamos con escasa información: aparte de la ubicación en la periferia de la ciudad, casi desconocida por la mayoría de cartageneros, solo podemos referirnos a los trabajos más generales de los rrom de Colombia y Bogotá (Caballero, 2001; González, 2012). La ciudad alberga igualmente hablantes de LSC (lengua de señas de Colombia). Según datos proporcionados por estudiantes de la Universidad de Cartagena, hay instituciones educativas con intérpretes a través de los cuales los que se busca la inclusión de población sorda en el sistema de educación básica para oyentes. Hay, igualmente, población extranjera que ha migrado en olas sucesivas de larga data, como la de los chinos que se han integrado al sistema económico de la ciudad mediante el comercio (Matos, 2015), o las migraciones más recientes de los venezolanos que huyen de la situación política y económica de su país en busca de oportunidades. Esta población en situación de vulnerabilidad soporta, además, la acogida parcial o el rechazo de sus anfitriones. También a diario la ciudad recibe gran afluencia de turistas de diferentes nacionalidades. Es en gran medida alrededor de este perfil ( $c f$. "Cartagena de Indias, Distrito Cultural y Turístico") que la ciudad se organiza. Finalmente, otras 
poblaciones también se han asentado como minorías. Tal es el caso de indígenas de los Andes como las nasas y los ingas. De estas poblaciones se tiene noticia a través de los estudiantes que los tienen como vecinos en diferentes puntos de la ciudad-región cartagenera.

Por lo demás, según la Red Nacional de Información (2018) una buena proporción de la población que se desplaza, alrededor de mil, son víctimas del conflicto armado interno del país.

Es necesario señalar que las lenguas y la diversidad lingüística colombianas están amparadas por la Constitución de 1991, la suscripción al convenio 169 de la OIT y los desarrollos en materia lingüística de la Carta Política que prevé la ley 1381 de 2010 (Ley de lenguas). Constatamos, sin embargo, que la visión de la realidad sociolingüística del país que subsume este marco legal no contempla explícitamente la evolución acelerada de las dinámicas de poblamiento y (re)configuración de las ciudades marcadas por las dinámicas arriba mencionadas.

En fin, cabe recalcar que los diagnósticos para obtener perfiles sociolingüísticos generales de las ciudades contribuyen no solo a visibilizar la presencia de estas poblaciones sino también a proporcionar una descripción al servicio de estas poblaciones y de instancias privadas y públicas locales de Cartagena (Secretarías de cultura, Programa de asuntos étnicos, de educación, de salud; divisiones de Bienestar estudiantil de los centros universitarios; instituciones educativas con hablantes de lenguas étnicas). Asimismo, estos diagnósticos sirven como punto de referencia y orientación para la propuesta e implementación de medidas tendientes a preservar a nivel local la diversidad lingüística y sociocultural y garantizar un ejercicio pleno de la ciudadanía, dando cumplimiento al marco legal nacional del que se dispone.

\section{Marco teórico para un perfil sociolingüístico}

La sociolingüística (Thomason \& Kaufman, 1988; Appel \& Muysken, 1987), la sociología del lenguaje (cf. Bourdieu, 1982), la antropología lingüística (Duranti, 2001 (1997)) y la etnografía de la comunicación (Saville-Troike, 2005; Guber, 2011) proporcionan conceptos operacionales y metodologías para la descripción y análisis del uso que hacen los hablantes de sus recursos lingüísticos en diferentes contextos, que pueden ser determinados o no por el contacto de lenguas y de poblaciones. En estas disciplinas, los contextos de interacción se perfilan como espacios de tensión que generan acomodaciones, resistencias, y cambios en las formas lingüísticas y en las comunidades. 
Como se ha venido insistiendo, se busca en este trabajo integrar nuevas concepciones de estas transdisciplinas que cuestionan y evalúan modelos tradicionales de análisis, que pueden vehicular concepciones heredadas de dinámicas históricas coloniales (cf. Labov, 2006) y limitaciones a la hora de explicar la complejidad de situaciones plurilingües y multiculturales. Es, pues, posible integrar los avances que este campo ha conocido de descripción y reflexión en las últimas décadas, al formular estudios para situaciones de convergencia de poblaciones y lenguas basados en perspectivas y conceptos alternativos de análisis (Léglise, 2017; Léglise y Sánchez, 2018). Entre estos últimos, encontramos la noción de "superdiversidad" en las urbes (Vertovec, 2007; Blommaert y Rampton, 2011) que amplía el campo de investigación del contacto de lenguas y culturas, otrora discretizables a partir de un referente ideal de monolingüismo: mezcla y alternancia de códigos. También frente a designaciones y concepciones como "tercer mundo" se plantean perspectivas analíticas y metodológicas integradoras de la perspectiva de investigadores y actores del sur (cf. Global South). Se exponen categorías lingüísticas aprehendidas desde "hibridación" (Sánchez, 2015; Godenzzi, 2017), ya no desde la mezcla o cambio de códigos. Así, se replantean los repertorios abarcando todas las posibles variedades lingüísticas (diatópicas, diafásicas, diastráticas, diasistémicas): repertorios lingüísticos superdiversos o truncados (Busch, 2015; Blommaert, 2010), polylanguaging (Jørgensen et al., 2011) translanguaging (García et Wei, 2014); o la construcción de nuevas significaciones a partir de recursos de las distintas variedades lingüísticas convergentes.

En fin, más allá de las poblaciones y códigos en contacto, a partir de una dimensión amplia se quiere enfocar las prácticas comunicativas heterogéneas (cf. Pratiques langagières hétérogènes (Léglise, 2017). La propuesta actual consiste en aproximarnos a las prácticas comunicativas, entre ellas las lingüísticas, de la ciudad de Cartagena, a la luz de referentes teóricos y metodológicos, que aluden a paradigmas alternativos. Entre ellos se encuentra igualmente la revisión del concepto y el alcance de la "comunidad" desde las perspectivas de interacciones lingüísticas (Gumperz, 1962), comunicativas (Gumperz, 1968), histórica, sociocultural (Causse, 2009) y de prácticas (Holmes y Meyerhoff, 2011).

\section{Metodología propuesta}

Para el desarrollo de las diferentes tareas de recolección y análisis de datos recurriremos básicamente a métodos sociolingüísticos de variables sociales y prácticas lingüísticas y en general comunicati- 
vas (Labov, 1986) y etnográficos (Guber, 2001; Saville-Troike, 1993; Duranti, 2001) y a la expansión de la concepción de repertorios lingüísticos propuesta por Busch (2015) que implica considerar las experiencias de vida de los hablantes desde las múltiples dimensiones que lo componen. Desde esta orientación, entre las estrategias, herramientas e instrumentos recurriremos a las siguientes: observación participante, desarrollo de cuestionarios y guías para encuestas y entrevistas semiestructuradas, representaciones gráficas y discursivas de experiencia lingüística, toma de notas, diario de campo, en donde se prevé la participación de miembros de las comunidades en papeles activos. Se prevé la grabación de intercambios, concebidos desde el marco amplio de las prácticas heterogéneas, en diferentes espacios de interacción (escuelas, universidades, lugares de trabajo, dispensarios y centros de salud, centros culturales, entidades públicas, etc.).

Nos serviremos de programas informáticos para la transcripción (Elan), la identificación y frecuencia léxica (AntConc) y la inserción de metadatos (Arbil). Estas herramientas han sido desarrolladas durante las dos últimas décadas y son constantemente actualizadas por un equipo técnico y científico del Instituto Max Planck (ver el sitio web TLA: The Language Archive). Para la ubicación de las diferentes poblaciones podremos recurrir a Google Earth.

Los grupos etnolingüísticos que por ahora se han identificado en la ciudad son los arriba mencionados, a saber: criollos palenquero y raizal, lengua de señas de Colombia, indígenas de la Sierra Nevada de Santa Marta, población zenú, nasas e ingas. Considerando las limitaciones que representa un equipo de trabajo reducido para el mapeo y la descripción de las diferentes poblaciones que coexisten en la ciudad, se seleccionaría una muestra representativa de las poblaciones que acabamos de enumerar y se preverían etapas sucesivas de trabajo con diferentes grupos etnolingüísticos. Aunque hace parte del perfil sociocultural de Cartagena la presencia histórica de migrantes chinos y creciente de venezolanos, no serían abordados en esta propuesta. De la situación sociolingüística de población china se encuentra en curso un trabajo de grado en la Universidad de Cartagena.

El marco de trabajo para este tipo de trabajo colaborativo, participativo y de empoderamiento de los hablantes sería el semillero de investigación "Dinámicas lingüísticas y culturales en Cartagena", con actividades de transferencia y divulgación del conocimiento científico. La naturaleza participativa y colaborativa de este trabajo implicaría 
proporcionar a los diferentes actores involucrados la información general y la específica requerida sobre el proyecto (objetivos, resultados esperados, metodología, desarrollo, medios).

\section{Proyecciones e impacto de un diagnóstico sociolingüístico de Cartagena}

Desde la academia y a partir de un trabajo colaborativo con las poblaciones y comunidades, piezas del mosaico sociocultural de la ciudad, que acepten el reto de participar en este estudio, la propuesta busca ocuparse de esta realidad ofreciendo un primer esbozo del panorama sociolingüístico de la ciudad de Cartagena que contribuya a las diferentes poblaciones convergentes a (re)conocer(se) y a valorar(se) desde su diversidad sociocultural.

En este sentido, mediante un diagnóstico sociolingüístico se puede contribuir a la construcción de la ciudad-región del Distrito turístico y cultural de Cartagena como una urbe socioculturalmente sostenible, que gracias a la armonía de sus relaciones logre un mutuo reconocimiento, así como el respeto, la valoración de la diferencia y la inclusión ( $c f$. Objetivos de desarrollo sostenible de la UNESCO). Cabe señalar que las dinámicas de la movilidad, aceleradas y cambiantes, exigen una constante actualización de la información aportada por el diagnóstico de las poblaciones paulatinamente recibidas e instaladas en la ciudad y un seguimiento de la vitalidad de sus lenguas, tarea que puede preverse desde una instancia académica.

Los resultados obtenidos -en distintas ciudades- podrían tener como impacto un trabajo mancomunado entre instancias académicas, autoridades locales y poblaciones concernidas. La información actualizada sería punto de partida para la toma de decisiones e implementación de medidas en materia de derechos y acceso a servicios públicos por parte de estas poblaciones. Por otro lado, se podrían multiplicar los medios de divulgación y apropiación social del conocimiento a través de actividades dirigidas a la sociedad general, así como a instancias administrativas locales y nacionales $(c f$. programas distritales y nacionales de asuntos étnicos) sobre la diversidad, la importancia de preservarla y las acciones específicas que pueden proponerse para garantizar un acceso equitativo a los servicios y la ciudadanía.

La lengua es el medio privilegiado que atraviesa toda interacción y actividad humanas y en esa medida, la lingüística y sus interdisciplinas se constituyen en materia de referencia obligada a la hora de adelantar investigaciones en campos transdisciplinares amplios, que 
pueden incluso ir más allá de las ciencias humanas y sociales. Este trabajo podría pues convocar el saber hacer de diferentes programas o carreras (Lingüística y Literatura, Historia, Sociología, Filosofía), facultades (Ciencias Humanas, Ciencias Sociales y Educación) e instancias como los centros de bienestar estudiantil e inclusión de minorías.

En Cartagena, consideramos que a mediano y largo plazo los resultados de este estudio podrían ser consultados y articulados a iniciativas de investigación e intervención social de grupos académicos nacionales y supranacionales interesados en tareas paralelas y complementarias de las que proponemos en nuestro estudio. Sin ser exhaustivos y solo a título ilustrativo, entre ellos encontramos instancias como el SIRE y Bienestar universitario de la Universidad de Cartagena y grupos de investigación de la universidad, a saber: Cultura, ciudadanía y poder en contextos locales; Ciencia tecnología y sociedad, con su línea de investigación: Desarrollo local, organización social y prosocialidad; el Observatorio de Desplazamiento, Conflictos y Construcción de Paz, Territorios vulnerables, desarrollo humano sostenible. En este listado puede también entrar la Coalición Latinoamericana y Caribeña de Ciudades contra el Racismo, la Discriminación y la Xenofobia, iniciativa impulsada por la UNESCO, en el año 2004, a la cual la ciudad de Cartagena se ha suscrito.

Esta propuesta de aproximación a la diversidad sociocultural y lingüística de Cartagena, en particular el registro de interacciones comunicativas y su análisis, contribuirá a confirmar o afinar la pertinencia del aparato analítico y las herramientas metodológicas que actualmente se ofrecen para el estudio de estos fenómenos. Al contrastar nuestros resultados con los obtenidos en otras ciudades del mundo, por ejemplo, Cayena en la Guayana francesa (Alby y Léglise, 2014) o Lima (Godenzzi, 2017), se genera retroalimentación y nuevas experiencias que permiten debatir y contrastar el conocimiento validado en otros países del mundo con situaciones similares.

Descripciones del panorama sociocultural de las ciudades, en general y de las prácticas comunicativas en particular, permitirían tener una mejor comprensión, tanto de las manifestaciones y orígenes de las relaciones asimétricas entre poblaciones y variedades lingüísticas como de la amenaza inminente y creciente para la preservación de la diversidad sociocultural del país. Y contribuirían, por otro lado, a la retroalimentación y revisión de los marcos teóricos y metodológicos que se estudian este tipo de dinámicas. 


\section{Bibliografía}

Alby, S. y Léglise, I. (2014). Pratiques et attitudes linguistiques des enseignants. La gestion du plurilinguisme à l'école en Guyane. En V. Nocus I, J. y M. Paia (Ed.), L'école plurilingue en outre-mer: Apprendre plusieurs langues, plusieurs langues pour apprendre. (pp. 245-267). Rennes: Presses Universitaires de Rennes.

Appel, R. y Muysken, P. (2005). Language Contact and Bilingualism. Amsterdam: Amsterdam University Press.

Ardila, 0. (2012). Lenguas en contacto en Colombia: una perspectiva histórica y social. En C. Patiño y J. Bernal (Coord.), El Lenguaje en Colombia (pp. 431-443). Bogotá: Instituto Caro y Cuervo, Academia Colombiana de la Lengua.

Arrázola, R. (1970). Palenque, primer pueblo libre de América. Cartagena: Ediciones Hernández.

Blommaert, J. (2010). The Sociolinguistics of Globalization. Cambridge, New York, Melbourne, Madrid, Cape Town, Singapore, São Paulo, Delhi, Dubai, Tokyo: CUP.

Blommaert, J., and B. Rampton. (2011). Language and Superdiversity. Diversities 13(2), 1-21.

Bourdieu, P. (1982). Ce que parler veut dire. L'économie des échanges linguistiques. Paris: Fayard.

Busch B. (2015). Expanding the Notion of the Linguistic Repertoire: On the Concept of Spracherleben. The Lived Experience of Language. Applied Linguistics, 1(20), 340-358. Doi:10.1093/ applin/amv030

Caballero, 0. (2001). Aproximación sociolingüística a la comunidad gitana Rom de Colombia. Forma y función, (14) 67-82. Recuperado de https://revistas.unal.edu.co/index.php/formayfuncion/article/view/17216.

Chaparro, J. (2007). Acercamiento sociolingüístico a Zumbico, una vereda del Resguardo-Municipio de Jambaló. Bogotá: Universidad Nacional de Colombia.

Causse, M. (2009). El concepto de comunidad desde el punto de vista socio-histórico-cultural y lingüístico. En Centro de información 
y Gestión Tecnológica, Ciencia en su PC, (3), 12-21. Recuperado de http://www.redalyc.org/articulo.oa?id=181321553002

DANE (Departamento Administrativo Nacional de Estadística). [s.f.]. Los Grupos Étnicos de Colombia en el Censo de 1993. Análisis de Resultados. Bogotá: División de Ediciones DANE.

DANE (Departamento Administrativo Nacional de Estadística). (2007). Colombia: una nación multicultural. Su diversidad étnica. Bogotá: División de Ediciones DANE.

Del Castillo, N. (1982). Esclavos negros en Cartagena y sus aportes léxicos. Bogotá: Instituto Caro y Cuervo.

Dieck, M. (2011). La época de formación de la lengua de Palenque: datos históricos y lingüísticos. Forma y función, 21(1), 11-24. Recuperado de https://revistas.unal.edu.co/index.php/formayfuncion/article/view/29100

Duranti, A. (2001). Antropología lingüística. Madrid: Cambridge University Press.

Fagua, D. (2004). Diagnóstico Sociolingüístico del Departamento del Amazonas. Los Lagos (periferia de Leticia): Contacto y cambio. Bogotá: Universidad Nacional de Colombia. Encuentros Colección Tesis Laureadas. Recuperado de http://www.bdigital. unal.edu.co/1301

Ferguson, Ch. (1959). Diglosia. En R. Garvín y Y. Lastra (Eds.), (1984) Antología de estudios de Etnolingüística y sociolingüística (pp. 325-340). México: UNAM

Flórez, A. Indígenas zenúes luchan por un hogar en Cartagena. El Universal 13/08/2012. Recuperado de https://www.eluniversal.com.co/cartagena/indigenas-zenues-luchan-por-un-hogar-en-cartagena-87226-AWEU171364

Friedemann, N. (1983). Palenque de San Basilio, historia y organización social. En N. de Friedemann, y C. Patiño, Lengua y Sociedad en el Palenque de San Basilio (pp. 17-82.). Bogotá: Instituto Caro y Cuervo.

García, O. et Wei, L. (2014). Translanguaging: Language, Bilingualism and Education. Basingstoke: Palgrave Pivot. 
Godenzzi, J. (2017). Relatos y recursos lingüísticos de la inserción urbana: tres migrantes quechua-hablantes en Lima. Visitas al Patio, (11), 11-37. Recuperado de https://revistas.unicartagena.edu.co/index.php/visitasalpatio/article/ view/1894/1627. DOI: https://doi.org/10.32997/20270585-vol.0-num.11-2017-1894

Goez, A. Indígenas del cabildo Zenú acuerdan hoja de ruta para su reubicación. El Universal 17/08/2018. Recuperado de https:// www.eluniversal.com.co/cartagena/indigenas-del-cabildo-zenu-membrillal-acuerdan-hoja-de-ruta-para-su-reubicacion-285374-DUEU402177

González, M. (2012). Los gitanos y su lengua. En C. Patiño y J. Bernal (Coord.), El lenguaje en Colombia. Tomo 1: Realidad lingüística de Colombia (pp.737-755). Bogotá: Instituto Caro y Cuervo, Academia colombiana de la lengua.

Guber, R. (2001). La etnografía: método, campo y reflexividad. Bogotá: Grupo Editorial Norma. Recuperado de https://tihuicampos.files.wordpress.com/2014/10/rosana-guber-la-etnografc3ada-mc3a9todo-campo-reflexividad.pdf

Gumperz, J. (1974 [1962]). Tipos de comunidades lingüísticas. En R. Garvin y Y Lastra (Eds.), Antología de estudios de Etnolingüística y sociolingüística (pp. 235-246). México: UNAM,

Gumperz, J. (1968). The speech community. En International Encyclopedia of social sciences (pp. 381-386). Nueva York: MacMillan.

Harrison, K. David. (2016). Cuando mueren las lenguas: la extinción de los idiomas en el mundo y la erosión del conocimiento humano. Bogotá: Universidad de los Andes (Trad. Juan Fernando Merino).

Heller, M. (2013). Language and Dis-Citizenship. Canada, Journal of Language, Identity \& Education, 12(3), 189-192. DOI: 10.1080/15348458.2013.797272. Recuperado de http://dx. doi.org/10.1080/15348458.2013.797272

Holmes, J. y Meyerhoff, M. (2011). La comunidad de práctica: teorías y metodologías en investigación de la lengua y género. Portal de Lenguas de Colombia: diversidad y contacto. [Traducción de Holmes \& Meyerhoff. (1999) Language in Society, 173-183]. Recuperado de http://www.lenguasdecolombia.gov.co 
IOM (International Organization for Migration) y Agencia de migración de la ONU. (2018). World migration report 2018. Recuperado de https://publications.iom.int/system/files/pdf/wmr_2018_ en.pdf

Jørgensen J. N., Sif Karrebaek M., Malai Madsen L. et Spindler Moller J. (2011), Polylanguaging in Superdiversity. Diversities 13(2), 23-37. Recuperado de www.unesco.org/shs/diversities/vol13/ issue $2 /$ art2

Labov, W. (2006). Principles of Linguistic Change. Vol. 2: Social Factors. Malden, Mass.: Blackwell.

Labov, W. (1986). Modelos sociolingüísticos. Madrid: Cátedra.

Landaburu, J. (2004-2005). Las lenguas indígenas de Colombia: presentación y estado del arte. Amerindia, 29(30), 3-22. Recuperado de https://www.vjf.cnrs.fr/sedyl/amerindia/articles/pdf/A_29-30_00.pdf

Léglise, I. and Sánchez Moreano, S. (2018). From Varieties in Contact to the Selection of Linguistic Resources in Multilingual Settings. Identity and Dialect Performance, edited by Reem Bassiouney (pp. 141-159). New York: Routledge Taylor and Francis.

Léglise, I. (2017). Multilinguisme et hétérogénéité des pratiques langagières. Nouveaux chantiers et enjeux du Global South. Langage et Société, Maison des Sciences de L'homme (pp. 251266). Recuperado de https://hal.archives-ouvertes.fr/hal01527466/document

Matos, C. (2015). Cómo ser colombiano sin dejar de ser chino. Migración de chinos a Cartagena de Indias. 1940-1960. Bogotá: Universidad Nacional de Colombia.

Ministerio de Cultura. (2011). Patrimonio cultural inmaterial en Colombia. Bogotá: Nomos S.A. Recuperado de http://patrimonio. mincultura.gov.co/Documents/convencionpolitica\%20PCI.pdf

Navarrete, M. (2008). San Basilio de Palenque: memoria y tradición. Cali: Universidad del Valle. 
Oakes, L. y Warren, J. (2007). Language, citizenship and identity in Quebec. Houndmills, Basingstone, Hampshire, Nueva York: Palgrave Macmillan.

Pachón, X. y Correa, F. (Coord. y Ed.). (1997). Lenguas amerindias: condiciones sociolingüísticas en Colombia. Bogotá: Instituto Caro y Cuervo, ICANH.

Pérez, A. (2012). De la diferencia como amenaza a la diversidad como potencia: reflexiones en torno a la relación entre ciudadanía intercultural e intervención en lo social. Eleuthera, (7), 264-281.

Programa de Protección a la Diversidad Etnolingüística (PPDE). (2013). Informe preliminar sobre la primera campaña del autodiagnóstico sociolingüístico del PPDE (versión preliminar). Bogotá: Ministerio de Cultura. Recuperado de http://www. observatorioetnicocecoin.org.co/descarga/informe_preliminar_autodiagnostico_sociolinguistico.pdf

Ramírez, H. (2003). Diagnóstico sociolingüístico de Cumaribo, zona de contacto indígena - Colono, Vichada. Bogotá: Universidad Nacional de Colombia. Encuentros Colección Tesis Laureadas. Recuperado de http://www.digital.unal.edu.co/dspace/bitstream/10245/858/2/01PREL01.pdf

Red Nacional de Información y Registro Único para las Víctimas. (2018). Registro único de la población desplazada (RUPD) (actualizado al 1 de abril). Recuperado de https://rni.unidadvictimas.gov.co/RUV

Reichel-Dolmatoff, G. y A. (1957). Reconocimiento arqueológico de la hoya del río Sinú. Revista Colombiana de Antropología, (6), 31-149.

Rey, L. (2001) Diagnóstico sociolingüístico de la Chorrera-Amazonas. Bogotá: Universidad Nacional de Colombia.

Rodríguez, S. (2004). De lo visible a lo invisible. Un acercamiento sociolingüístico a tres asentamientos de la ribera del Amazonas colombiano: Mocagua, Ronda y La Libertad. Bogotá: Universidad Nacional de Colombia.

Salgado, N. (2011). Migración palenquera a la ciudad de Cartagena 1960-2000. Cartagena de Indias: Universidad de Cartagena. 
Sánchez Moreano, Santiago. 2017. Enoncés de type OV et positionnements sociaux dans l'espagnol parlé par les Quichuas équatoriens à Cali, Colombie. Sociolinguistics Studies. Equinox, 11(1), 65-105. https://doi.org/10.1558/sols.30850.

Sánchez Moreano, S. (2018). Negociación de posicionamientos sociales (Stances) a través del debilitamiento del fonema /s/ en el español hablado por Los quichuas ecuatorianos en Cali (Colombia). Pragmática Sociocultural / Sociocultural Pragmatics, 6(1), 33-70. https://doi.org/10.1515/soprag-2017-0019

Saville-Troike, M. (2005). Etnografía de la comunicación una introducción. Buenos Aires: Prometeo Libros.

Solano, F. (2008). Elementos para un diagnóstico sociolingüístico del nasa yuwe en el resguardo municipio de Jambaló, departamento del Cauca. Caso: vereda El Trapiche. Bogotá: Universidad Nacional de Colombia.

Schwegler, A. y Moñino, Y. (Coord.) (2002). Palenque, Cartagena y Afro-Caribe: historia y lengua. Madrid: Max Niemeyer Verlag.

Thomason, S. y Kaufman, T. (1998). Language Contact, Creolization, and Genetic Linguistics. Berkeley, Los Ángeles: University of California Press.

TLA (The Language Archive), sitio web del Instituto Max Planck. Disponibles en: https://tla.mpi.nl/tools/tla-tools/

Turbay, S. (1992). Los indígenas zenúes. Geografía Humana de Colombia. Región Andina Central, 6(3). Bogotá: Instituto Colombiano de Cultura Hispánica.

UNESCO. (2015). Objetivos de desarrollo sostenible. Recuperado de https://es.unesco.org/sdgs

Vertovec, S. (2007). New Directions in the Anthropology of Migration and Multiculturalism. Ethnic and Racial Studies, 30(6), 961-978. 